Sebastien Deglise

Salah D. Qanadli

Elena Rizzo

Nicolas Ducrey

Francesco Doenz

Claude Haller

Alban Denys

Jean-Marc Corpataux

\section{Long-term follow-up of surgically excluded popliteal artery aneurysms with multi-slice CT angiography and Doppler ultrasound}

Received: 18 January 2005

Revised: 1 September 2005

Accepted: 13 September 2005

Published online: 17 January 2006

(C) Springer-Verlag 2006

S. Deglise $\cdot$ C. Haller · J.-M. Corpataux

Department of Thoracic

and Vascular Surgery, CHUV,

Lausanne, Switzerland

S. D. Qanadli $(\bowtie) \cdot$ E. Rizzo •

F. Doenz $\cdot$ A. Denys

Department of Radiology,

University Hospital CHUV-

University of Lausanne,

46 Rue du Bugnon,

1011, Lausanne, Switzerland

e-mail: salah.qanadli@chuv.ch

Tel.: +41-21-3144560

Fax: +41-21-3144554

N. Ducrey

Department of Angiology, CHUV,

Lausanne, Switzerland

\begin{abstract}
The purpose of this study was to evaluate the role of multi-slice computed tomography (MSCT) angiography in the follow-up of popliteal artery aneurysms (PAAs) that have been operated on. Aneurysm exclusion and progression, graft patency and graft-related complications were analyzed. Fourteen patients with 21 surgically excluded PAAs were evaluated with MSCT angiography with slice thickness of $1.25 \mathrm{~mm}$. The mean follow-up time was 67 months. MSCT demonstrated blood flow in six nonexcluded PAAs (24\%), with an average increase in the diameter of $21 \mathrm{~mm}$ over time. Fifteen PAAs demonstrated no blood flow and revealed an average decrease of $7 \mathrm{~mm}$ in diameter. The origin of this residual perfusion was demonstrated, and collaterals were involved in five of six non-excluded
\end{abstract}

PAAs. In addition, MSCT demonstrated three graft stenoses. Furthermore, two occluded grafts were visualized. Twenty-four percent of the patients after surgical exclusion of PAAs revealed residual perfusion within the aneurysmal sac during follow-up, with a significant increase in the aneurysmal size with MSCT. Moreover, evaluation of the graft patency could also be done as could demonstration of anastomotic abnormalities. Thus, MSCT might be considered as a new tool to evaluate residual collateral feeding of popliteal aneurysmal sac and could be useful in identification and localization of feeding vessels.

Keywords Multi-slice CT scan . Popliteal artery aneurysm · Graft . Anastomosis

\section{Introduction}

Popliteal artery aneurysms (PAAs) are the most frequent peripheral artery aneurysms [1] and are potentially dangerous lesions with high frequency of thromboembolic complications (18-77\%) and amputation risk (10-67\%) [2-9]. In cases of symptomatic PAAs, diameter exceeding $20 \mathrm{~mm}$ or presence of a mural thrombus [10-12], the procedure of choice is exclusion of the aneurysm and reverse saphenous vein bypass grafting. Some authors [3, $4,13,14]$ have demonstrated that initially small asymptomatic aneurysms mostly remained unchanged when untreated, whereas others recommended prophylactic repair, justified by the risk of chronic embolization from the aneurysm $[5,6,15,16]$.
The major long-term complications of the PAAs that have been operated on have been graft stenosis and thrombosis due to intimal hyperplasia. However, some cases of symptomatic enlargement and rupture of already excluded aneurysms have been reported [8,17]. The origin of this recurrence is not fully understood. Moreover, some authors $[18,19]$ have shown that more than $30 \%$ of ligated PAAs increased in size during follow-up, sometimes requiring re-intervention, which was associated with a higher operating risk. Thus, they recommended long-term surveillance of all PAAs with contrast enhanced CT or Doppler ultrasound (DU). Few reports exist in the literature about CT reliability in detecting popliteal aneurysmal disease, especially using multi-slice CT (MSCT) angiography $[20,21]$. To our knowledge, none of them evaluated 
Table 1 Baseline characteristics of the patients enrolled in this study at the time they underwent initial surgery for PAA

\begin{tabular}{ll}
\hline Characteristic & \\
\hline Age (years) & $66 \pm 12$ \\
Men/women & $14 / 0$ \\
Risk factors (\% of patients) & 11 \\
Smoking & 9 \\
Hypertension & 3 \\
Diabetes & 10 \\
Dyslipidemia & 5 \\
Associated abdominal aorta aneurysm & $26 \pm 12$ \\
Initial PAA diameter (mm) & \\
Run-off & \\
Three vessels & 8 \\
Two vessels & 9 \\
One vessel & 4 \\
Surgical characteristics & \\
Exclusion & 18 \\
Resection & 3 \\
Reversed saphenous vein & 18 \\
In situ saphenous vein & 2 \\
Prosthesis & 1
\end{tabular}

${ }^{a}$ Defined as the number of patent tibial vessels in continuity from the trifurcation to the ankle [10]

the potential of $\mathrm{CT}$ in the post-operative surveillance of excluded PAAs.

The aim of this study was to evaluate the role of MSCT angiography in the post-operative surveillance of excluded

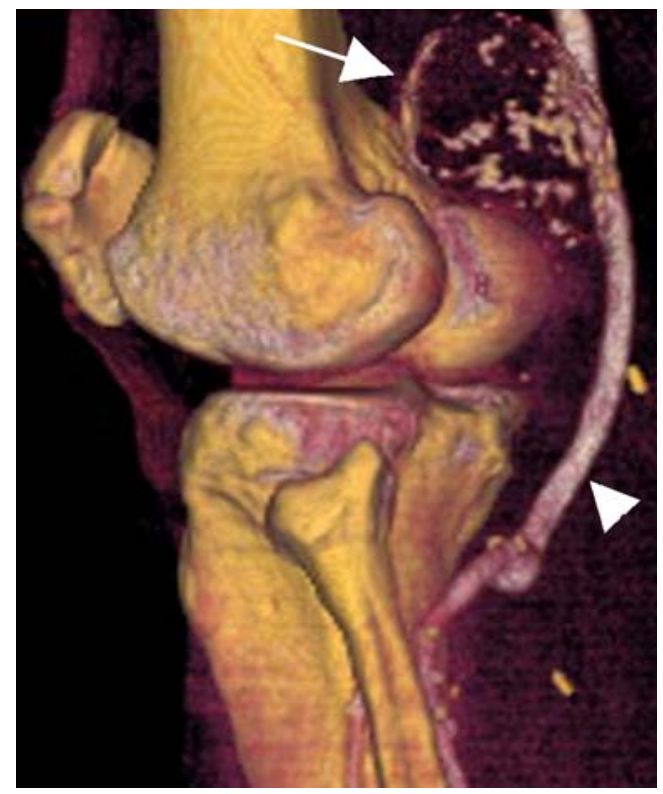

Fig. 1 An excluded PAA (arrow) with no intrasac residual blood flow depicted. The patent venous bypass graft (arrowhead) from femoral artery to the infra-genicular popliteal artery is well demonstrated

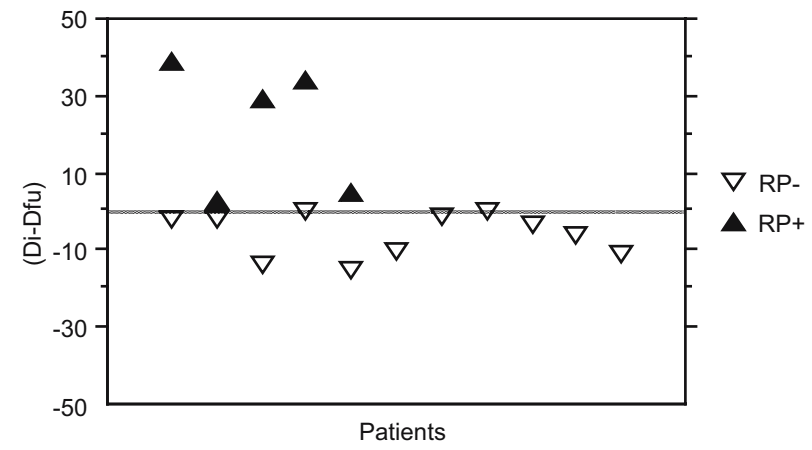

Fig. 2 Distribution of the difference between initial (Di) and follow-up (Dfu) diameters (in millimeters) of the PAAs (Di-Dfu) according to the presence or not of residual perfusion (RP) in the aneurysmal sac. Notice the correlation between the presence of residual perfusion $(R P+)$ and the diameter increase at follow-up

PAAs using a high resolution with specific regard to the assessment of the aneurysm exclusion and progression, graft patency and graft-related complications.

\section{Materials and methods}

\section{Patients}

Data for patients with PAA admitted to our University Hospital between January 1991 and December 2001 were reviewed. Thirty-seven patients with 53 surgically excluded PAAs were identified. Three patients died in the postoperative period and one during the follow-up period. Four underwent amputations. Five patients were lost to follow-up because they moved to another country, and four refused to participate in the study. In the remaining patients, seven with renal failure were excluded. Thus, 14 patients, with a mean age of 66 years (range 45 to 86 years) and with 21 surgically excluded PAAs were enrolled in this study. All patients gave their informed consent before follow-up examinations. Approval was obtained from the local ethics committee.

Table 2 Relationships between initial run-off, the diameter of the PAA and the detection of residual blood flow on MSCT

\begin{tabular}{llll}
\hline $\begin{array}{l}\text { Initial run-off } \\
\text { (number of } \\
\text { patent vessels) }\end{array}$ & $\begin{array}{l}\text { Number of PAAs } \\
\text { with increased/ } \\
\text { decreased diameter }\end{array}$ & $\begin{array}{l}\text { RBF detectable } \\
\text { on MSCT } \\
\text { (number of } \\
\text { PAAs) }\end{array}$ & $\begin{array}{l}\text { No RBF on } \\
\text { MSCT } \\
\text { (number of } \\
\text { PAAs) }\end{array}$ \\
\hline 1 & $0 / 4$ & 0 & 4 \\
2 & $2 / 5^{\mathrm{a}}$ & 2 & 7 \\
3 & $3 / 2^{\mathrm{b}}$ & 4 & 4 \\
\hline
\end{tabular}

${ }^{a}$ In two cases no initial diameter was available

${ }^{b}$ In three cases no initial diameter measurement was available 
Fig. 3 Residual blood flow in surgically excluded PAAs. Classification based on features of the feeding arterial branches and collateral supply. In type 0 , no RBF is depicted. a Type I: $\mathrm{RBF}$ is supported by the proximal anastomosis. b Type II: $\mathrm{RBF}$ is from collaterals originating proximally to the proximal anastomosis. c Type III: $\mathrm{RBF}$ is from collaterals originating distally to the distal anastomosis. $\mathbf{d}$ Type IV: RBF is supported by the distal anastomosis. e Type V: RBF is from to at least two different sources
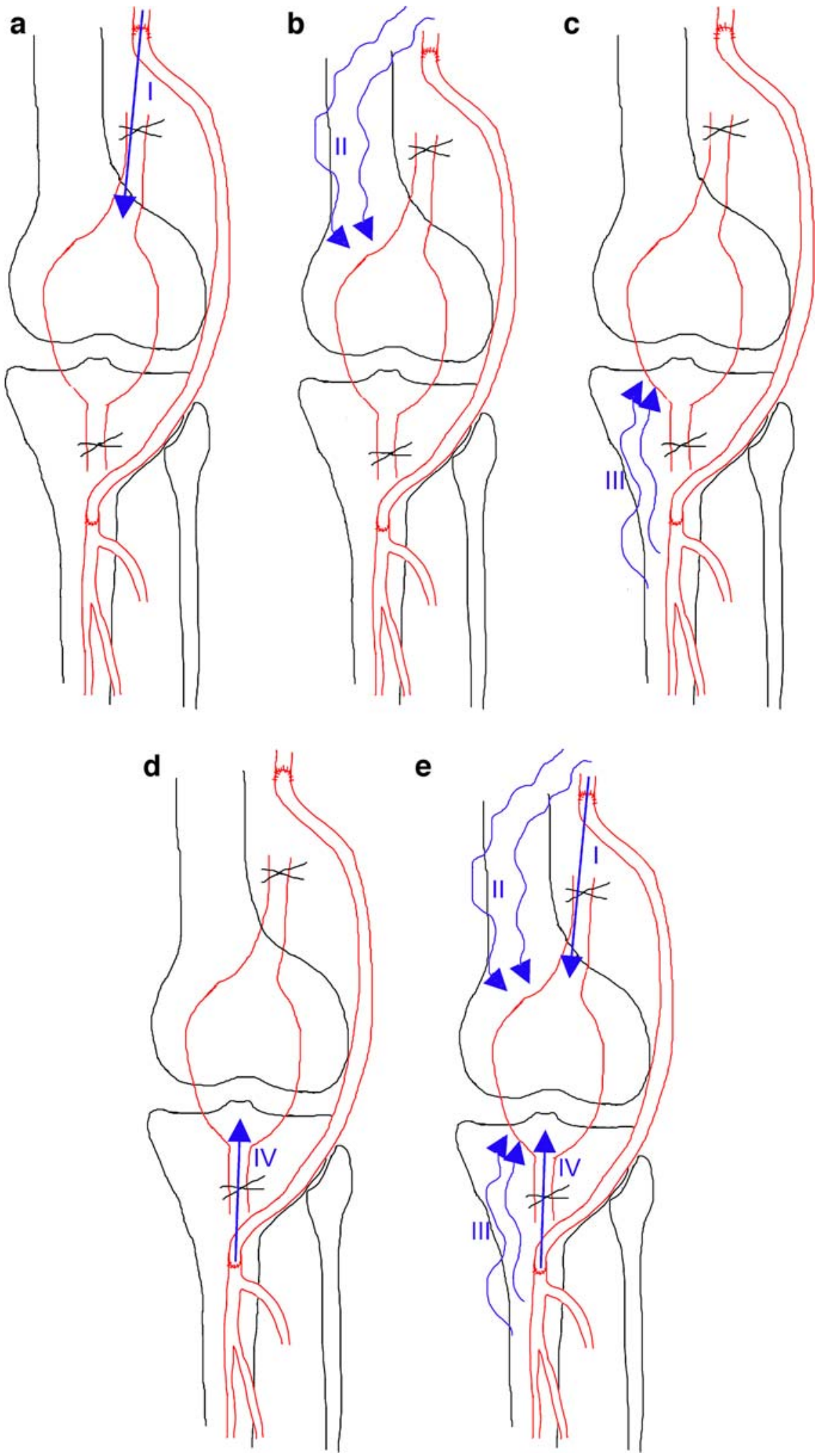

e

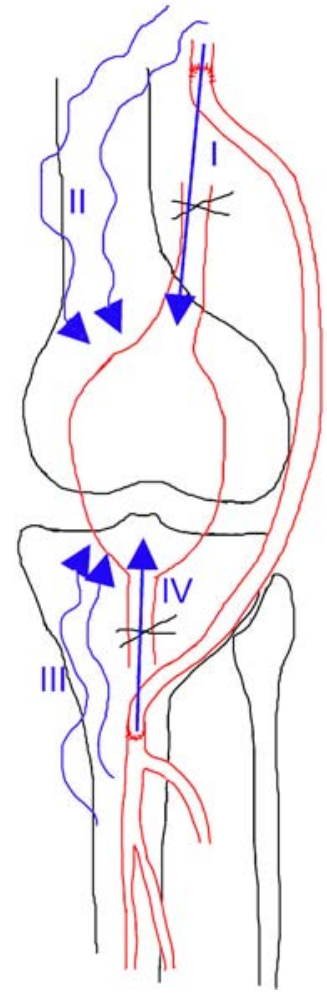


For each patient clinical examination, DU and MSCT angiography were carried out from January 2003 to May 2003. The mean follow-up period from surgical exclusion to evaluation with MSCT was 67 months (range 25 to 190 months).

At the time of the MSCT scan, among the 21 limbs that were operated on, 18 were asymptomatic and two presented claudication, Fontaine stage IIa. The last patient complained of local discomfort in the popliteal fossa, with signs of venous compression. Table 1 summarizes the clinical characteristics of patients with excluded PAAs undergoing MSCT follow-up study.

\section{MSCT scans}

MSCT scans were performed on 16-row detector Lightspeed Pro (GE Healthcare, Milwaukee, USA), using high spatial resolution in all patients, with slice thickness of $1.25 \mathrm{~mm}$. To optimize vascular enhancement in the region of interest two dynamic consecutive series after a single bolus test of $30 \mathrm{ml}$ of contrast material (Iopentol 300, GE Biosciences, Milwaukee, USA) pulsed by $50 \mathrm{ml}$ saline solution at a rate of $4 \mathrm{ml} / \mathrm{s}$ were done. The first one was set at the celiac trunk level and the second one at the popliteal arteries. From the density-time curves generated, the time needed by contrast material to move from the aorta to the popliteal arteries was calculated as the difference between the time to maximum enhancement in the popliteal arteries and the time to maximum enhancement in the abdominal aorta. Acquisition parameters (rotation time and table speed) were then selected to have an acquisition time as near as possible to the calculated time. A total of $120 \mathrm{ml}$ to
$150 \mathrm{ml}$ of contrast material was necessary to obtain CT angiography from the abdominal aorta to below the knee arterial tree. Images were reconstructed every $1.25 \mathrm{~mm}$. Combined analysis of axial images, 2D reformations and $3 \mathrm{D}$ reconstructions using volume rendering techniques or maximum intensity projection algorithm was used to assess the aneurysm, grafts and collateral supply whenever they existed. At least two radiologists analyzed, in consensus, each examination. Maximum diameter measurements were obtained in all cases and reported as mean $\pm \mathrm{SD}$.

\section{Doppler ultrasound}

Doppler ultrasound scans were done by vascular specialists using a Vingmed sound, system FiVe ultrasound machine with $5 \mathrm{MHz}$ probes (Vingmed, System 5, Norway). Graft patency and sites of anastomosis were systematically assessed. If signs of residual blood flow (RBF) were depicted inside the aneurysm, or if the aneurysm size increased, the maximum diameter was obtained.

\section{Results}

Assessment of aneurysm exclusion and aneurysm progression

MSCT showed that 15 of the 21 PAAs (71\%) were completely excluded without any RBF depicted inside the aneurysm (Fig. 1). The maximum diameter decreased in 11 of these PAAs and had a mean difference between the preoperative maximum diameter and the maximum diameter
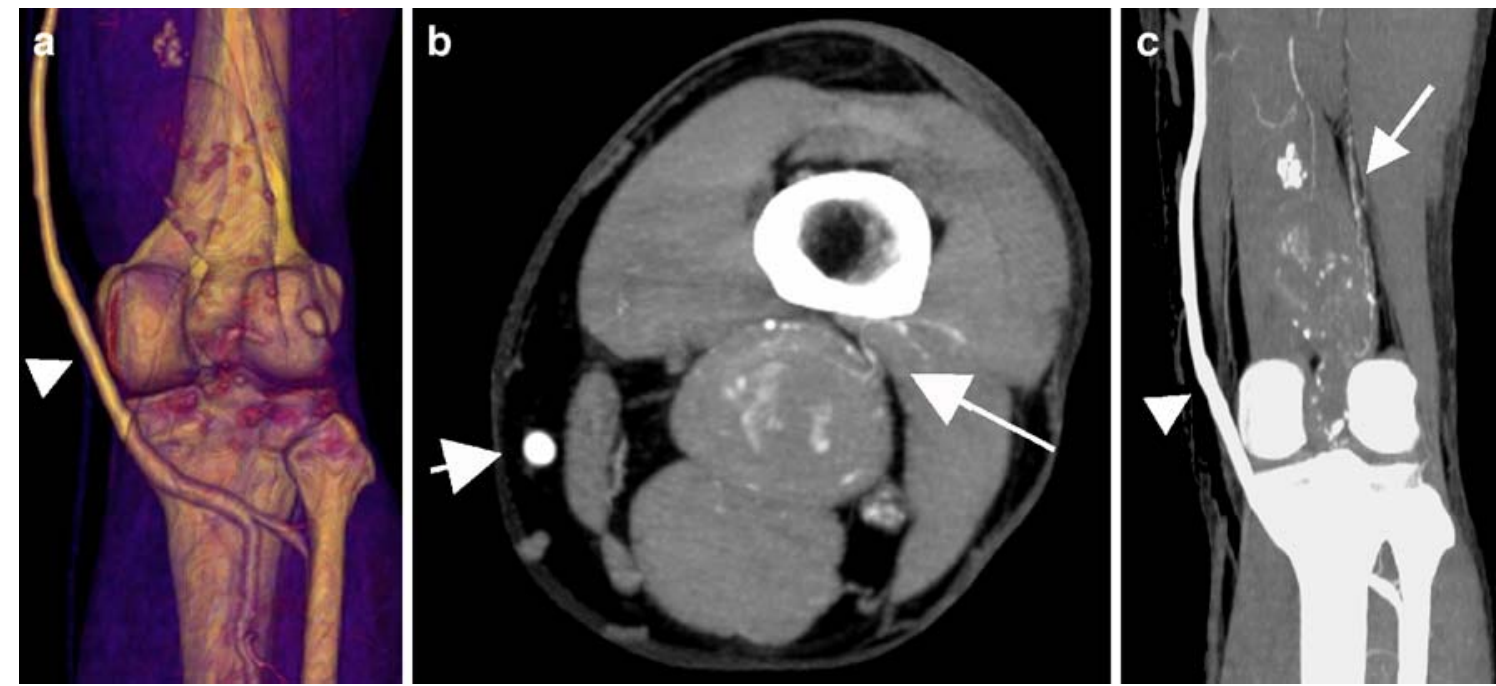

Fig. 4 Residual blood flow type II in surgically excluded PAAs. a Three-dimensional reconstruction of the patent venous graft (arrowhead) showing no abnormalities of the distal anastomosis. b,c Persistent aneurysmal sac perfusion was depicted on the axial transverse view using a maximum-intensity projection algorithm (b) and on the coronal view (c). The coronal view well showed the feeding arterial branches arising from proximal collaterals (arrow) 
at the follow-up study of $7 \mathrm{~mm}$ (range 0.5 to $15 \mathrm{~mm}$ ). In the remaining four patients, no pre-operative measurement of the diameter was available. In six PAAs (29\%), RBF of the aneurysmal sac was demonstrated. In all cases but one (Fig. 2), where no initial diameter was known, RBF was associated with an increase in the maximum diameter with a mean value of $21 \mathrm{~mm}$ (range 2 to $38 \mathrm{~mm}$ ). Only two cases of increasing diameter in MSCT were depicted on DU $(40 \mathrm{~mm}$ and $65 \mathrm{~mm})$ and characterized as positive RBF. However, the origin of RBF was not clearly demonstrated by DU. It has been assumed to be probably from collaterals. In the remaining 19 other cases, no RBF was observed at DU examination.

In the PAAs still perfused the surgical procedure used was femoro-popliteal bypass, and all but two anastomoses performed were termino-terminal. The initial aneurysm size exceeded $20 \mathrm{~mm}$ in five of the six patients. In one patient no initial diameter measurement was available. In four cases of RBF, extensive ectasia of ilio-femoral arteries were seen at the initial status. No relationship was demonstrated between the run-off and changes in aneurismal diameters. Among the four patients with poor run-off (only one patent distal vessel), there were no increases in diameter (Table 2).

In only one patient, an aneurysm with RBF and significant progression (maximum diameter of $60 \mathrm{~mm}$ ) induced pain of the popliteal fossa. The patient was treated by endovascular embolization of collaterals feeding the aneurysm.

In order to characterize the source of the RBF, features of the feeding arterial branches and collateral supply were graded as follow (Fig. 3): (1) type 0, no RBF depicted;
Fig. 5 Residual blood flow type $\mathrm{V}$ in surgically excluded PAAs. Multiple sources of the residual perfusion were depicted and characterized on maximumintensity projection algorithm reconstructions on the axial view $(\mathbf{a}, \mathbf{b})$ and the coronal view (c) as well as on the $3 \mathrm{D}$ reconstruction $(\mathbf{d})$
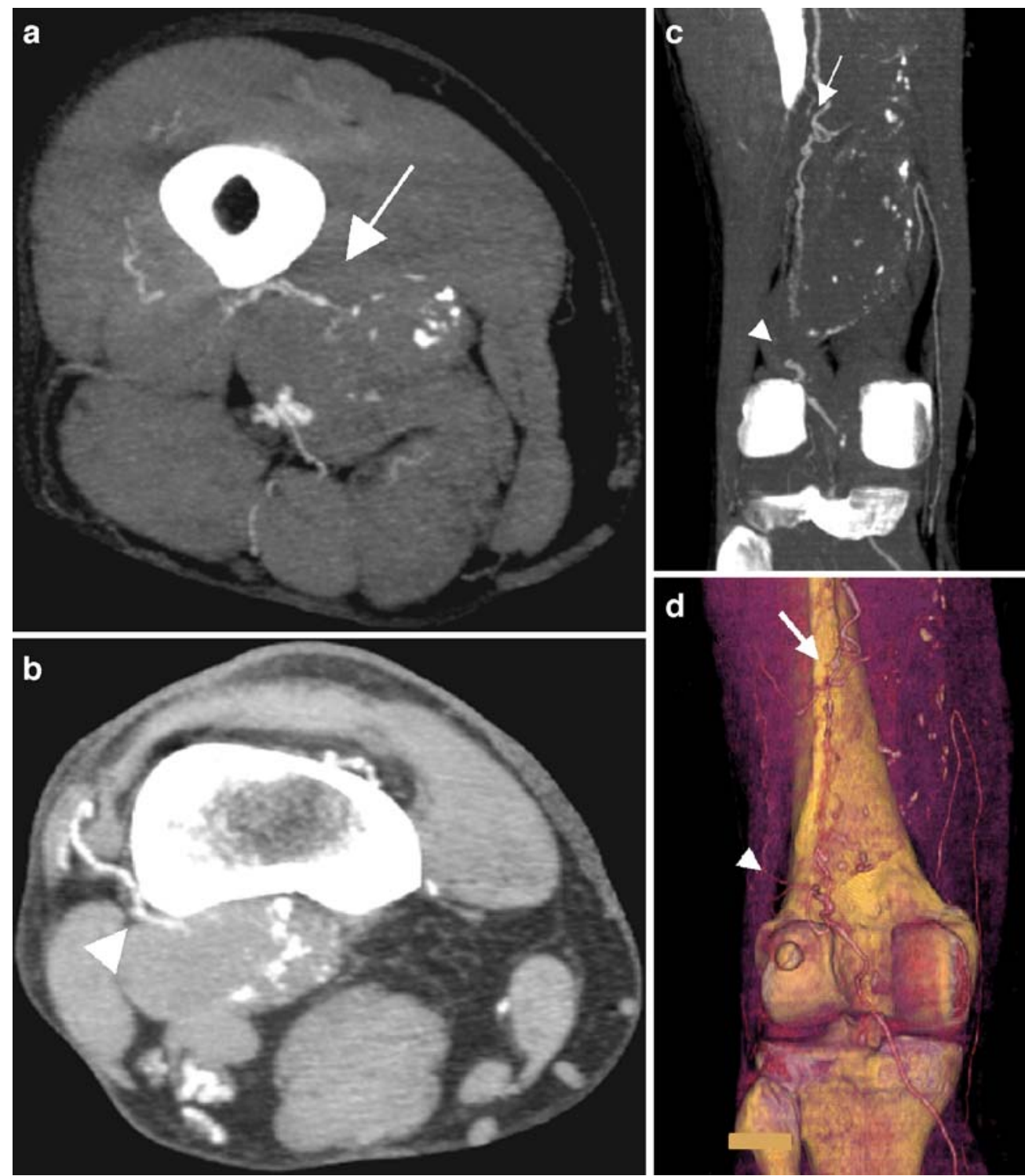
Table 3 Distribution of the patients presenting a non-excluded PAA according to the type of source of the RBF

\begin{tabular}{ll}
\hline Types & Number of cases \\
\hline I & 0 \\
II & 1 \\
III & 2 \\
IV & 1 \\
V & 2 \\
\hline
\end{tabular}

type I, RBF was supported by the proximal anastomosis; (2) type II, RBF was supported by collaterals originating proximally to the proximal anastomosis; (3) type III, RBF was supported by collaterals originating distally to the distal anastomosis (Fig. 4); (4) type IV, RBF was supported by the distal anastomosis; (5) type V, at least two different sources were found (Fig. 5). MSCT well characterized the $\mathrm{RBF}$, and Table 3 shows the distribution of RBF type found in our group.

Graft patency and graft-related complications

MSCT demonstrated that $19(90 \%)$ grafts were still patent and two $(10 \%)$ grafts were occluded. In both cases of graft occlusion, patients remained asymptomatic and no additional treatment was carried out. One patient had a prosthetic bypass and had already presented an episode of occlusion 1 year before, which had been treated by thrombolysis and angioplasty of a distal anastomosis stenosis, with unsatisfactory result. The other one had a femoro-tibioperoneal trunk bypass that required additional thrombectomy of the distal artery during the initial operation, and the patient was receiving anticoagulation therapy. According to MSCT, DU demonstrated the same two occluded grafts.

Three non-significant stenoses were depicted on MSCT scans confirmed by DU.

\section{Discussion}

A high risk of limb loss is associated with PAA, especially when acute thrombosis occurs. The risk of amputation varies between 24\% and $69 \%$ [2-7]. Moreover, untreated PAAs carry some risks of rupture or nerve compression, with potential limb dysfunction. For these reasons, management of PAAs must be carefully carried out. Some authors $[2,5,6,11,15,16,22]$ have shown that patency rates are better in elective cases, preventing distal embolization and a poor run-off $[2,11,23,24]$. Others risk factors justifying surgical approach are a diameter of more than $20 \mathrm{~mm}$, a mural thrombus or a poor run-off, because they are predictive factors of acute thrombosis if not treated $[12,23,24]$. Exclusion of PAA is widely recommended.

In the past, only graft patency and limb salvage rates were analyzed as outcomes. Nevertheless, some authors reported some cases of rupture of a previously ligated PAA $[8,17]$. This was uncommon, and it could be explained by the fact that patients died before the onset of the complication. Recently, Ebaugh et al. [18] reported an increase in mean aneurysmal diameter after exclusion and bypass grafting procedures in $32 \%$ of cases. Not only could an ageing population explain this increase but also they are more often searched for. Furthermore, non-excluded PAA is a specific and probably underestimated complication after ligation of PAA, and it should be searched for by radiological means. Landry et al. [25] showed that the longterm success of bypass graft procedures for the lower extremities was predicted by an aggressive regimen of DU surveillance, allowing early identification of graft-related lesions and native artery abnormalities before graft occlusion. DU could also demonstrate intrasac blood flow, as in the series of Kirkpatrick et al. [19].

Piccoli et al. demonstrated that MSCT allowed depiction of peripheral aneurysms with information about the vessel wall, especially the presence of calcium [20]. This had already been reported by Beregi et al. [21]. However, new advances in multi-row detector technology, especially 16row CT scans as used in our study, allows larger volume acquired with a high resolution at similar or shorter acquisition times than the CT scans reported in previous studies. This advantage allows assessment of the entire arterial system, from abdominal aorta to the below-theknee arteries, including popliteal region, in-flow and outflow that help to characterize the treated PAAs, especially in the case of RBF. In our series, MSCT angiography permitted us to detect all non-excluded PAAs and, thus, showed its superiority over DU. To our knowledge no study has compared the value of CT angiography as an alternative to DU in the follow-up of popliteal artery diseases. However, the majority of reports on DU performance to detect endoleaks after endovascular repair of abdominal aortic aneurysm [26-31] found inferior sensitivity and specificity compared to CT angiography. Nevertheless, contrast agents (Levovist) seem to increase the sensitivity of this color-flow DU, but with the risk of more false-positive results [32]. However, CT angiography carries some disadvantages, such as increased radiation exposure, potential contrast allergy and worsening of renal insufficiency. Another alternative to CT angiography could be magnetic resonance angiography (MRA), especially in patients with renal impairment [33].

Six of the 21 PAAs $(29 \%)$ operated on in our series were not completely excluded at the time of follow-up, with a mean increase in diameter of $21 \mathrm{~mm}$ but with only one limb being symptomatic (5\%). No rupture was seen. This is in accordance with Kirkpatrick et al., who revealed that $33 \%$ of PAAs increased in size after ligation and bypass [19]. However, in their series, approximately half of the feeding aneurysms presented some local symptoms, and one rupture occurred. Furthermore, Metha et al. reported that $38 \%$ 
of PAAs that had been operated on presented persistent collateral flow, and $23 \%$ increased in size during a 2-year follow-up period [35].

The pathogenesis of aneurysmal recurrence and expansion is not fully understood. Several hypotheses exist. Although poor run-off has been described as a risk factor for occurrence of complications with popliteal artery aneurysm, it seems that there is no relationship with recurrence after previous ligation. In accordance with type II endoleaks appearing after PAAs, it is probably partly linked to persistent feeding of the aneurysmal sac from patent geniculate collateral vessels, which are not ligated during the initial operation. This filling increases pressure in the aneurysm, contributing to its unceasing expansion. This is in accordance with Metha et al., who identified the presence of geniculate arteries with retrograde flow in the sac at re-operation [35]. Although Ebaugh et al. [18] found no trend to suggest that retrograde filling predisposes to the growing of PAAs, we observed a relationship between increasing size and presence of RBF in the aneurysmal sac depicted by MSCT. Moreover, MSCT angiography using a high spatial resolution was reliable to characterize collateral supplies to the RBF in the aneurysmal sac. Based on anatomic type of collaterals and arterial branches, MSCT angiography findings clearly support the hypothesis that the collateral arterial is a source of the increase in the aneurysm diameter. Another theory is based on the concept of endotension, which was used when no blood flow was identified in the aneurysmal sac [36-38]. Kirkpatrick et al. [19] reported that $17 \%$ of PAAs with no intrasac RBF detected increased in size. Patent side branches resulted in maintenance of pressurization of the sac, inducing size increase without any detectable blood flow [18]. However, it could be assumed that insufficient sensitivity of CT angiography or Doppler ultrasound used in these studies limited flow detection in the aneurysm. In our series, we observed no patient with increased aneurysm diameter without RBF detected.

In the literature few reports about the management of such non-excluded PAAs exist, and guidelines are still lacking. According to the fact that approximately $50 \%$ of initially documented endoleaks spontaneously sealed during follow-up of endovascular exclusion of abdominal aneurysms [39], the hypothesis that some of the patent genicular branches, not ligated during surgical treatment of PAA, should also disappear early in the postoperative period could be considered. So, aggressive management should concern only persistent collaterals feeding a growing aneurysmal sac. In these cases, appropriate therapeutic options should be debated. Metha et al. proposed a posterior approach, with sac decompression [35]. In our experience MSCT provides useful information by depicting origin and localization of collaterals feeding the aneurysmal sac. Transcatheter embolization could be a reasonable and successful solution in type III RBF. Because the management varies, depending on the source of the RBF, MSCT also allows distinction between collateralbased perfusion and anastomosis-related residual feeding. The anastomosis-related residual feeding should be encountered no more, because termino-terminal anastomoses, with ligation of the aneurysm, are recommended. Nevertheless, if a re-intervention is necessary, more precise evaluation of the anatomy of the popliteal fossa, as obtained by three-dimensional reconstructions provided by MSCT, can be helpful.

In conclusion, because of the risk of aneurysmal recurrence after ligation and bypass of PAAs in approximately one-third of cases, and because of associated complications such as rupture, a program of life-long surveillance should be established. Because of its high spatial resolution, MSCT angiography is a new tool to identify RBF and characterize collateral feeding of the aneurysm. Although these findings have to be confirmed in larger series, MSCT angiography is a reliable method in the detection of nonexcluded PAAs, not only by providing precise information on diameter increase and graft-related complications but also on RBF detection and characterization that should be considered to define therapeutic options and follow-up strategy in these patients.

\section{References}

1. Evans WE (1982) Popliteal aneurysms. Grune and Sratton, New York, pp 487492

2. Carpenter JP, Barker CF, Roberts B, Berkowitz HD, Lusk EJ, Perloff LJ (1994) Popliteal artery aneurysms: current management and outcome. J Vasc Surg 19:65-73
3. Vermilion B, Kimmins SA, Pace WG, Evans WE (1981) A review of one hundred forty-seven popliteal aneurysms with long-term follow-up. Surgery 90:1009-1014

4. Szylagyi DE, Schwartz RL, Reddy DJ (1981) Popliteal arterial aneurysms: their natural history and management. Arch Surg 116:724-728
5. Dawson I, van Bockel H, Brand R, Terpstra JL (1991) Popliteal artery aneurysms. Long-term follow-up of aneurysmal disease and results of surgical treatment. J Vasc Surg 13:398407 
6. Dawson I, Sie R, van Baalen JM, van Bockel JH (1994) Asymptomatic popliteal aneurysm: elective operation versus conservative follow-up. Br J Surg 81:1504-1507

7. Whitehouse WM Jr, Wakefield TW, Graham LM, et al (1983) Limbthreatening potential of arteriosclerotic popliteal artery aneurysms. Surgery 93:694-699

8. Shortell CK, DeWeese JA, Ouriel K, Green RM (1991) Popliteal artery aneurysms: a 25 year surgical experience. J Vasc Surg 14:771-779

9. Gifford RW, Hines EA, Janes JM (1953) An analysis and follow-up study of 100 popliteal aneurysms. Surgery 33:193-284

10. Lowell RC, Gloviczki P, Hallett JW, Naessens JM, Maus TP, Cherry KJ, Bower TC, Pairolero PC (1994) Popliteal artery aneurysms: the risk of nonoperative management. Ann Vasc Surg 8:14-23

11. Duffy ST, Colgan MP, Sultan S, Moore DJ, Shanik GD (1998) Popliteal aneurysms: a 10-year experience. Eur J Vasc Endovasc Surg 16:218-222

12. Stiegler H, Mendler G, Baumann G (2002) Prospective study of 36 patients with 46 popliteal artery aneurysms with non-surgical treatment. Vasa 31:43-46

13. Hands LJ, Collins J (1991) Infra-inguinal aneurysms: outcome for patient and limb. Br J Surg 78:996-998

14. Bowyer RC, Cawthorn SJ, Walker WJ, Giddings AEB (1990) Conservative management of asymptomatic popliteal aneurysm. Br J Surg 77:1132-1135

15. Dawson I, Sie RB, van Bockel JH (1997) Atherosclerotic popliteal aneurysm. Br J Surg 84:293-299

16. Varga ZA, Locke-Edmunds JC, Baird RN (1994) A multicenter study of popliteal aneurysms. J Vasc Surg 20:171-177

17. Battey PM, Skardasis GM, McKinnon WM (1987) Rupture of a previously bypassed popliteal aneurysm: a case report. J Vasc Surg 5:874-875

18. Ebaugh JL, Morasch MD, Matsumura JS, Eskandari MK, Meadows WS, Pearce WH (2003) Fate of excluded popliteal artery aneurysms. J Vasc Surg 37:954-959
19. Kirkpatrick UJ, McWilliams RG, Martin J, Brennan JA, Gilling-Smith GL, Harris PL (2003) Late complications after ligation and bypass for popliteal aneurysm. Br J Surg 90:A496

20. Piccoli G, Gasparini D, Smania S, Sponza M, Marzio A, Vit A, Bazzocchi M (2003) Multislice CT angiography in the assessment of peripheral aneurysms. Radiol Med (Torino) 106:504511

21. Beregi JP, Djabbari M, Desmoucelle F, Willoteaux S, Wattine L, Louvegny S (1997) Popliteal vascular disease: evaluation with spiral CT angiography. Radiology 203:477-483

22. Roggo A, Brunner U, Ottinger LW, Largiader F (1993) The continuing challenge of aneurysms of the popliteal artery. Surg Gynecol Obstet 177:565572

23. Aldoori MI, Rahman SH (1999) Popliteal aneurysm: the need for vigilance. Age Ageing 28:5-7

24. Gouny P, Bertrand P, Duedal V, Cheynel-Hocquet C, Lancelin C, Escourolle F, Nussaume O, Vayssairat M (2000) Limb salvage and popliteal aneurysms: advantages of preventive surgery. Eur J Vasc Endovasc Surg 19:496-500

25. Landry GJ, Moneta GL, Taylor LM Jr, Edwards JM, Yeager RA, Porter JM (2002) Long-term outcome of revised lower-extremity bypass grafts. J Vasc Surg 35:56-63

26. Parent EN, Meier GH, Godziachvili V, LeSar CJ, Parker FM, Carter KA, Gayle RG, DeMasi RJ, Marcinczyk MJ, Gregory RT (2002) The incidence and natural history of type I and II endoleak: a 5-year follow-up assessment with color duplex ultrasound scan. J Vasc Surg 35:474-481

27. Wolf YG, Johnson BL, Hill BB, Rubin GD, Fogarty TJ, Zarins CK (2000) Duplex ultrasound scanning versus computed tomographic angiography for postoperative evaluation of endovascular abdominal aortic aneurysm repair. J Vasc Surg 32:1142-1148

28. McLafferty RB, McCrary BS, Mattos MA, Karch LA, Ramsey DE, Solis MM, Hodgson KJ (2002) The use of color-flow duplex scan for the detection of endoleaks. J Vasc Surg 36:100-104

29. Raman KG, Missig-Carroll N, Richardson T, Muluk SC, Makaroun MS (2003) Color-flow duplex ultrasound scan versus computed tomographic scan in the surveillance of endovascular aneurysm repair. J Vasc Surg 38:645-651
30. Pages S, Favre JP, Cerisier A, Pyneeandee S, Boissier C, Veyret C (2001) Comparison of color duplex ultrasound and computed tomography scan for surveillance after aortic endografting. Ann Vasc Surg 15:155-162

31. Sato DT, Goff CD, Gregory RT, Robinson KD, Carter KA, Herts BR, Vilsack HB, Gayle RG, Parent FN 3rd, DeMasi RJ, Meier GH (1998) Endoleak after aortic stent graft repair: diagno sis by color duplex ultrasound scan versus computed tomography scan. J Vasc Surg 28:657-663

32. McWilliams RG, Martin J, White D, Gould DA, Rowlands PC, Haycox A, Brennan J, Gilling-Smith GL, Harris PL (2002) Detection of endoleak with enhanced ultrasound imaging: comparison with biphasic computed tomography. J Endovasc Ther 9:170-179

33. Hingorani A, Ascher E, Markevich N, Kallakuri S, Schutzer R, Yorkovich W, Jacob T (2004) A comparison of magnetic resonance angiography, contrast arteriography, and duplex arteriography for patients undergoing lower extremity revascularization. Ann Vasc Surg 18:294-301

34. Rubin GD, Schmidt AJ, Logan LJ, Sofilos MC (2001) Multi-detector row CT angiography of lower extremity arterial inflow and runoff: initial experience. Radiology 221:146-158

35. Metha M, Champagne B, Darling RC, Roddy SP, Kreienberg PB, Ozsvath KJ, Paty PSK, Chang BB, Shah DM (2004) Outcome of popliteal artery aneurysms after exclusion and bypass: significance of residual patent branches mimicking type II endoleaks. J Vasc Surg 40:886-890

36. Schurink GW, van Baalen JM, Visser MJ, van Bockel JH (2000) Thrombus within an aortic aneurysm does not reduce pressure on the aneurysmal wall. J Vasc Surg 31:501-506

37. Meier GH, Parker FM, Godziachvili V, Demasi RJ, Parent FN, Gayle RG (2001) Endotension after endovascular aneurysm repair: the Ancure experience. J Vasc Surg 34:421-427

38. Veith FJ, et al (2002) Nature and significance of endoleaks and endotension: summary of opinions expressed at an international conference. J Vasc Surg 35:1029-1035

39. Mahmood A, Salaman R, Sintler M, Smith SRG, Simms MH, Vohra RK (2003) Surgery of popliteal artery aneurysms: a 12-year experience. J Vasc Surg 37:586-893 